\title{
An Experimental Investigation on the Acoustic and Thermal Properties of Copper Reinforced Sustainable Foam
}

\author{
Manshu Gupta*, Asim Sneh*, Yuvaraj L. \\ * Department of Mechanical Engineering, \\ SMBS, VIT University, Chennai, \\ Tamil Nadu, India 600127
}

\author{
Jeyanthi Subramanian ${ }^{* *}$ \\ Associate Professor, \\ Department of Mechanical Engineering, \\ SMBS, VIT University, Chennai, \\ Tamil Nadu, India 600127
}

\begin{abstract}
Organic foams with different proportions of copper powder are fabricated using a general mixing process. The physical, chemical properties and the sound absorption co-efficient of these foams are investigated. The FTIR test results indicate the presence of different organic functional groups in the flexible organic sustainable foam. Acoustic shielding test compares the sound absorption coefficient. Lee disc method is used to find the thermal shielding (Thermal Conductivity) of the samples fabricated. The sound absorption coefficient is found to increase with increase of copper percentage in the foam. The mechanical behavior is approximately same for the reinforced foams with different percentage of coppers and is similar to that of unreinforced foam. The thermal conductivity is found to increase with the increase in the percentage of copper in the foam thus unreinforced foam has better thermal shielding property.
\end{abstract}

Keywords- Sustainable organic foam, Energy absorption, Sound absorption coefficient, Porosity, Copper Powder, Acoustic Interference (AMI) Shielding, Frequency, thermal conductivity.

\section{INTRODUCTION}

In Modern World Noise is one of the big problems of the society therefore any unwanted sound is called Noise. There are numerous cases where decreasing noise level is of great significance. Loss of hearing is just a single impact of ceaseless introduction to excessive noise levels. Noise can interfere with sleep, speech, and cause discomfort and other non-auditory related issues [1-3]. Additionally, high levels of noise and vibration lead to structural failures as well as reduction in life span in many industrial equipment's. For instance, in control valves, the vibration caused by flow instability occasionally defects the feedback to the control system and resulting in extreme oscillations.

The significance of noise issues could be well understood by looking at regulations that have been passed by governments to restrict noise production in society. Industrial machinery, air/surface transportation and construction activities are assumed to be main contributors in noise production or so called "noise pollution" [4]. Therefore, thin, light weight and low cost composite materials that will absorb sound waves in wider frequency regions are strongly desired. In present situation, the vast majority of the acoustic protection material is produced using synthetic fibers which are risky to human health and environment [5]. Thus a sustainable material is required and organic foam can be that material. The organic foam synthesized is to be tested for shielding of Acoustic interference. The merits of using organic foam are that it is lightweight, flexible and eco-friendly. Four test samples are synthesized one of which is a flexible organic foam without additives, three of them are flexible foams with varying proportions of copper powder by weight, Various techniques are used to obtain the properties of the samples. An Acoustic shielding test Setup is used for testing the acoustic shielding capability of the material.

Global warming is an another big [6] issue with noise pollution therefore there is a requirement of a versatile material which has not only good sound absorption coefficient but also is a bad conductor of heat so that it not only protects a confined space from noise but also from heated outside. Sustainable PU foam is a bad thermal conductor of heat [7]. So both the problems can be sorted out by this material. Lee's Method is performed to find the thermal conductivity of the samples to insure that there is no significant increase in the thermal conductivity of the samples with the increase in the sound absorption coefficient if any. Though PU foams have sufficient strength [8] for its current applications but its strength may change with addition of different percentage of copper powder. This material can be used for many purposes ranging from sound insulation material for walls of buildings or cars to inner insulating material of airplanes and space shuttles. Even after being so much versatile the manufacturing cost of the material is very cheap and manufacturing very simple and very less time consuming. As is it sustainable so it's less harmful to the environment as well, which makes it a very good material with very vast range of applications.

\section{EXPERIMENTAL PROCEDURE}

\section{A. Fabrication of copper Foam}

The flexible foams had a common mixture of isocyanides and polyol in the ratio of 2:3. First of all, organic foam with no additives was prepared by adding the two compounds in a cuboidal mold with one face open and letting the reaction take place. The reaction is exothermic and carbon dioxide gas is released. The mixture is allowed to expand and is then removed from the mold and is prepared according to the required dimensions. Now, three different samples were prepared with different weight by weight percentages of copper powder, i.e., $3 \%, 5 \%$ and $10 \%$, in a similar manner as more than $10 \%$ of copper powder reaction were not able to complete and mixture was collapsed. The sample for preparation of rigid foam containing the copper powder was not able to complete the reactions and collapsed [10] 


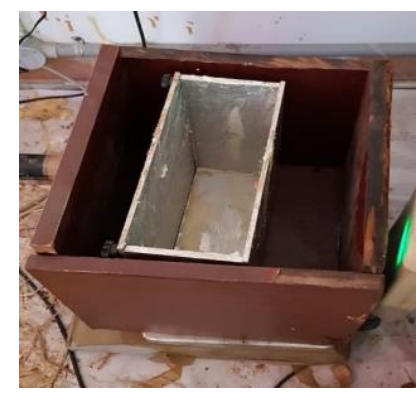

Figure 1. Specimen Mould

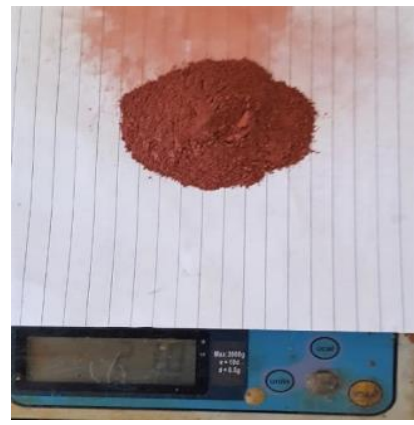

Figure 3. Measuring Apparatus

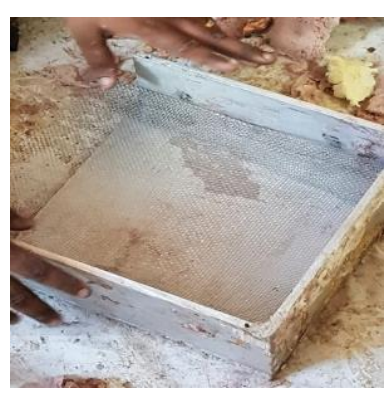

Figure 2. Al tray with wax On surface

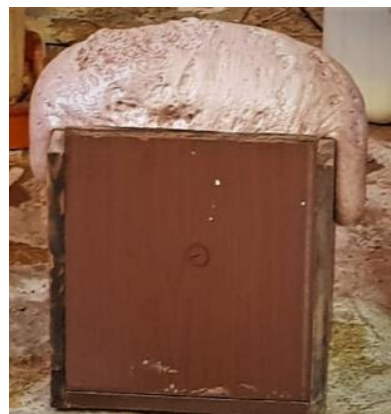

Figure 4. Final Product

\section{B. Acoustic shielding test Setup}

The sound abortion co-efficient is the absorbed fraction of the energy of a plane sound-wave when incident on the sample material. The co-efficient describes the ability of the material to absorb sound in a given frequency band. The sound absorbing coefficient of the material is measured using Impedance Tube Apparatus, which is a system consisting of a solid brass tube containing a speaker at the one end and the material sample whose properties are to be measured at the other end. The system has a pair of microphones separated by a finite distance connected to the brass tube with the help of microphone holders. These microphones are connected to a digital signal analyzer via signal conditioners (pre-amplifiers) and a data acquisition system. A function generator is used to power the speaker in the impedance tube. For the absorption coefficient a rigid backing is also used.

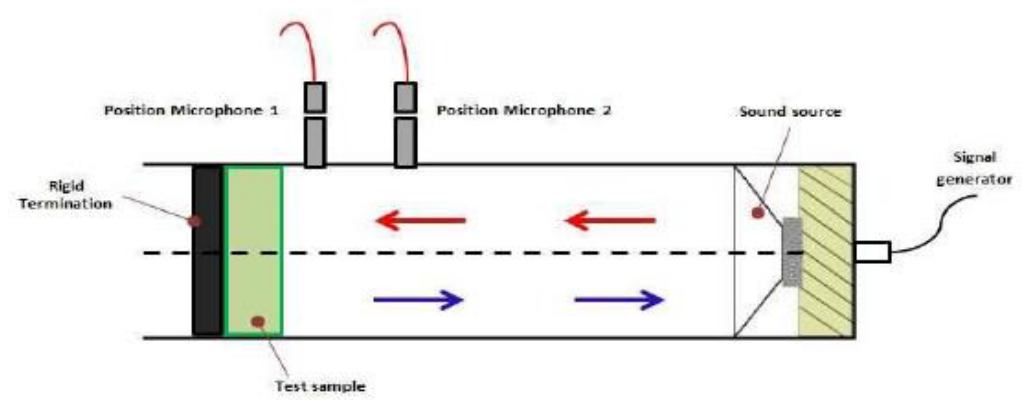

Figure 5. Schematic of Impedance Tube Apparatus

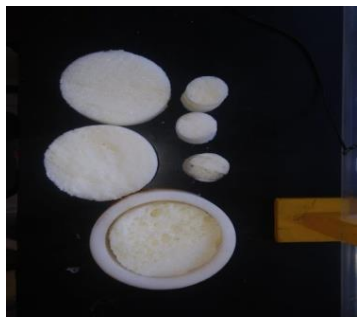

Figure 6. Test Sample Preparation

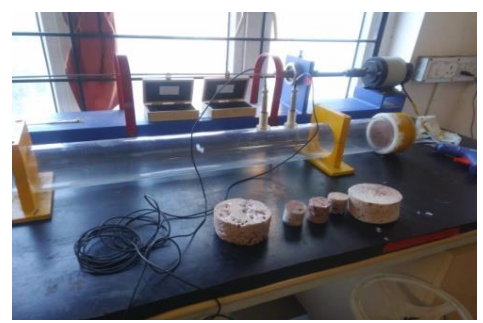

Figure 7. Acoustic Test Setup 


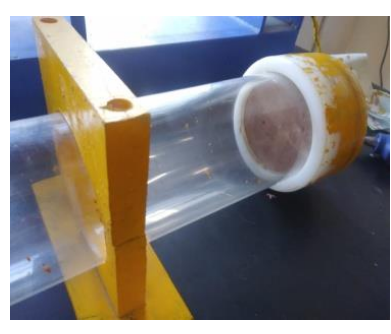

Figure 8. Sample in the Acoustic Test sample



Figure 9. Acoustic absorption coefficient spectrum analyzer

Table 1. Specifications of Impedance Tube Apparatus

\begin{tabular}{|c|c|}
\hline Parameter & Specification \\
\hline Impedance tube length & $900 \mathrm{~mm}$ \\
\hline Inside diameter & $56 \mathrm{~mm}$ \\
\hline Speaker frequency response range & $160-7000 \mathrm{~Hz}$ \\
\hline Signal generator & $200-6500 \mathrm{~Hz}$ \\
\hline Sweep in & Automated \\
\hline Number of microphones & $50 \mathrm{~mm}$ \\
\hline Sample holding unit & PC automated measurements \\
\hline Controls & MATLAB \\
\hline Software & MATL \\
\hline
\end{tabular}

Table 2. Test Observations of Sound Absorption Coefficient

\begin{tabular}{|c|c|c|c|c|}
\hline \multirow{2}{*}{$\begin{array}{c}\text { Frequency } \\
(\mathbf{H z})\end{array}$} & \multicolumn{4}{|c|}{$\mathbf{\% C u}$ in Flexible Foam } \\
\cline { 2 - 5 } & $\mathbf{0 \%}$ & $\mathbf{3 \%}$ & $\mathbf{5 \%}$ & $\mathbf{1 0 \%}$ \\
\hline 200 & 0.0512 & 0.1057 & 0.1352 & 0.1674 \\
\hline 250 & 0.0415 & 0.1321 & 0.1931 & 0.2233 \\
\hline 315 & 0.1243 & 0.1696 & 0.2697 & 0.2913 \\
\hline 400 & 0.1765 & 0.2237 & 0.3647 & 0.3724 \\
\hline 500 & 0.2395 & 0.2928 & 0.4636 & 0.4585 \\
\hline 630 & 0.3365 & 0.3868 & 0.5709 & 0.5572 \\
\hline 800 & 0.4136 & 0.5084 & 0.6818 & 0.6648 \\
\hline 1000 & 0.5453 & 0.6392 & 0.7801 & 0.7626 \\
\hline 1250 & 0.7386 & 0.7735 & 0.8665 & 0.8483 \\
\hline 1600 & 0.9312 & 0.9026 & 0.9374 & 0.9188 \\
\hline 2000 & 0.9473 & 0.9767 & 0.9689 & 0.9543 \\
\hline 2500 & 0.8805 & 0.9911 & 0.9645 & 0.9612 \\
\hline 3150 & 0.8492 & 0.9413 & 0.9322 & 0.9437 \\
\hline 4000 & 0.8201 & 0.8693 & 0.9140 & 0.9268 \\
\hline 5000 & 0.7663 & 0.8984 & 0.9625 & 0.9551 \\
\hline 6300 & 0.8228 & 0.9798 & 0.9898 & 0.9952 \\
\hline
\end{tabular}

C. Thermal conductivity test setup

Lee's method is used to find the thermal conductivity of bad conductors. Its setup has two parts as shown in figure 11. The lower part $\mathrm{C}$ is circular metal disc. The experimental specimen $\mathrm{G}$ is placed on it. The diameter of $\mathrm{G}$ is equal to that of $\mathrm{C}$ and thickness is uniform throughout. A steam chamber is placed on C. The lower part of the steam chamber, B is made of a thick metal plate of the same diameter as of $\mathrm{C}$. The upper part is a hollow chamber in which two side tubes are provided for inflow and outflow of steam. Two thermometers T1 and T2 are inserted into two holes in C and B, respectively. There are three hooks attached to $\mathrm{C}$. The complete setup is suspended from a clamp stand by attaching threads to these hooks. 


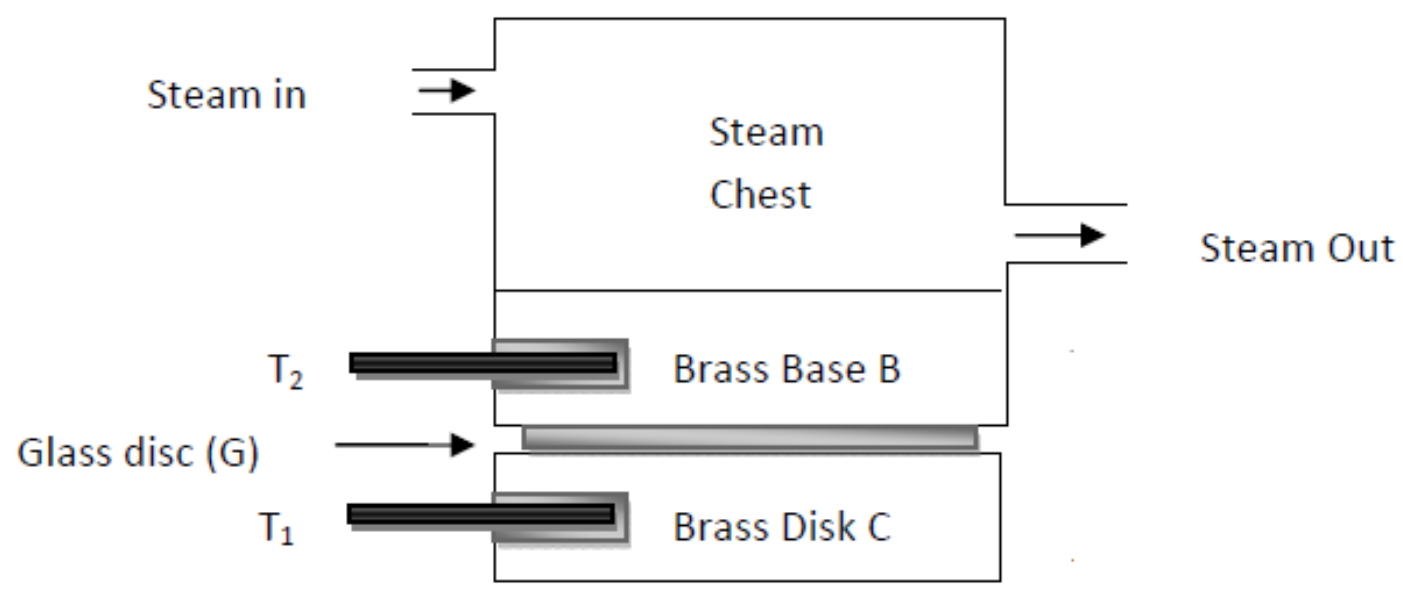

Figure 10. Schematic Lee's Disc method

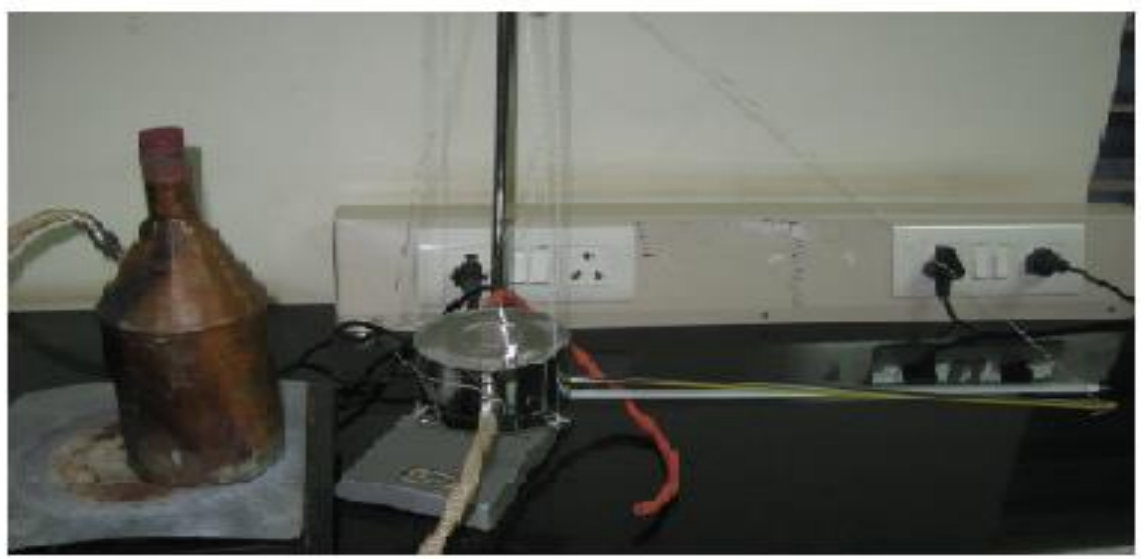

Figure 11. Lee's Disc method setup

$$
K=\frac{m s \frac{d T}{d t} x}{A(T 2-T 1)}
$$

where,

$\mathrm{K}=$ Thermal conductivity $\left(\mathrm{Wm}^{-1} \mathrm{k}^{-1}\right)$

$\mathrm{m}=$ mass of the lower disc $\mathrm{C}(\mathrm{kg})$

$\mathrm{s}=$ specific heat of lower disk $\mathrm{C}\left(\mathrm{J} \mathrm{Kg}^{-1} \mathrm{k}^{-1}\right)$

$\mathrm{x}=$ Thickness of the sample $\mathrm{G}(\mathrm{m})$

$\mathrm{A}=$ Area of the sample $\mathrm{G}\left(\mathrm{m}^{2}\right)$

$\mathrm{T} 1=$ Steady state temperature of disk $\mathrm{C}(\mathrm{K})$

$\mathrm{T} 2=$ Steady state temperature of disk B $(\mathrm{K})$

\section{A. FTIR Test}

\section{RESULTS AND DISCUSSION}

According to the plot obtained from the Fourier Transformation Infrared (FTIR) Spectrum, we have verified the functional groups present in the Copper reinforced sustainable foam. The plots obtained is shown below 


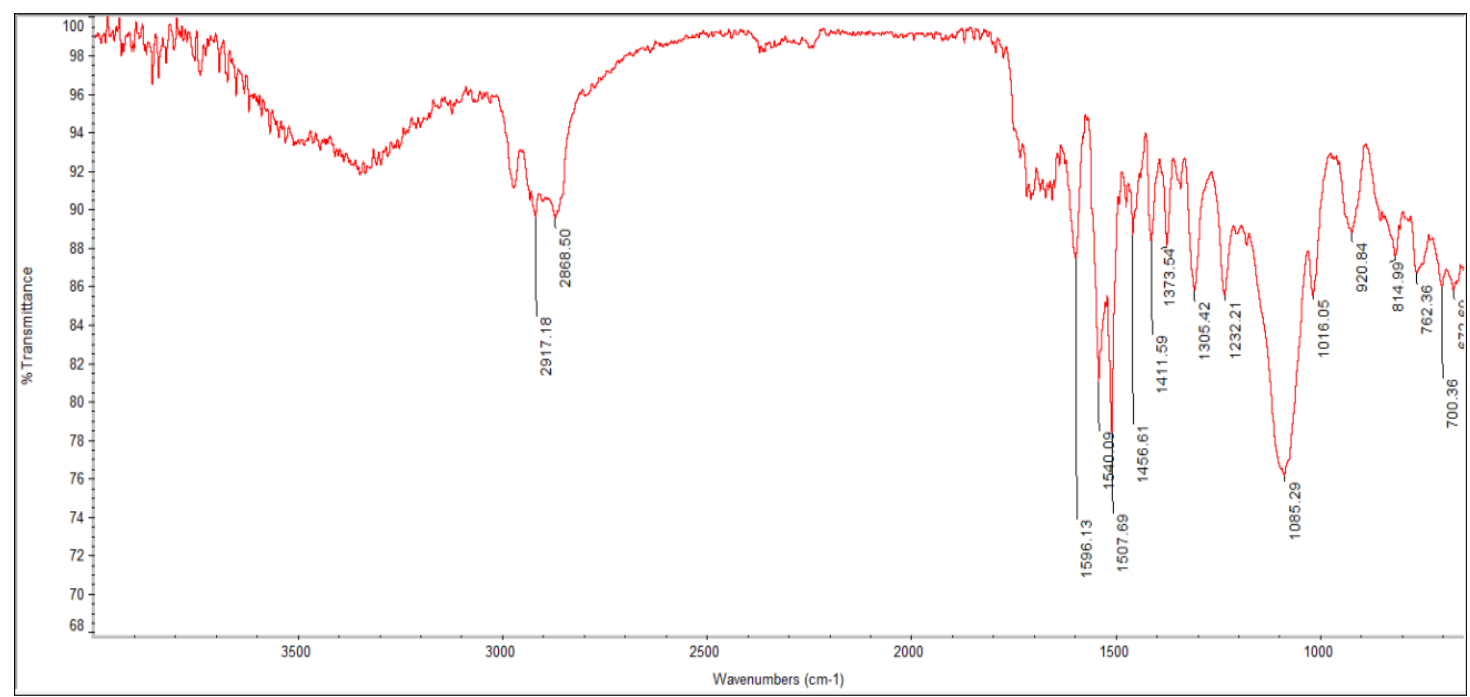

Figure 12. FTIR Spectrum of Flexible Organic Foam

From Figure 12, we can observe the broadening of the peaks in the range near $3500 \mathrm{~cm}-1$ which confirms the presence of $-\mathrm{OH}$ functional group. The stretching of the peaks near the range of $3000 \mathrm{~cm}-1$ confirms the presence of $-\mathrm{C}-\mathrm{H}$ groups. The absorption in the range of 2165-2110 cm-1 shows the presence of cyanide group.

\section{B. Acoustic Shielding Performance Test}

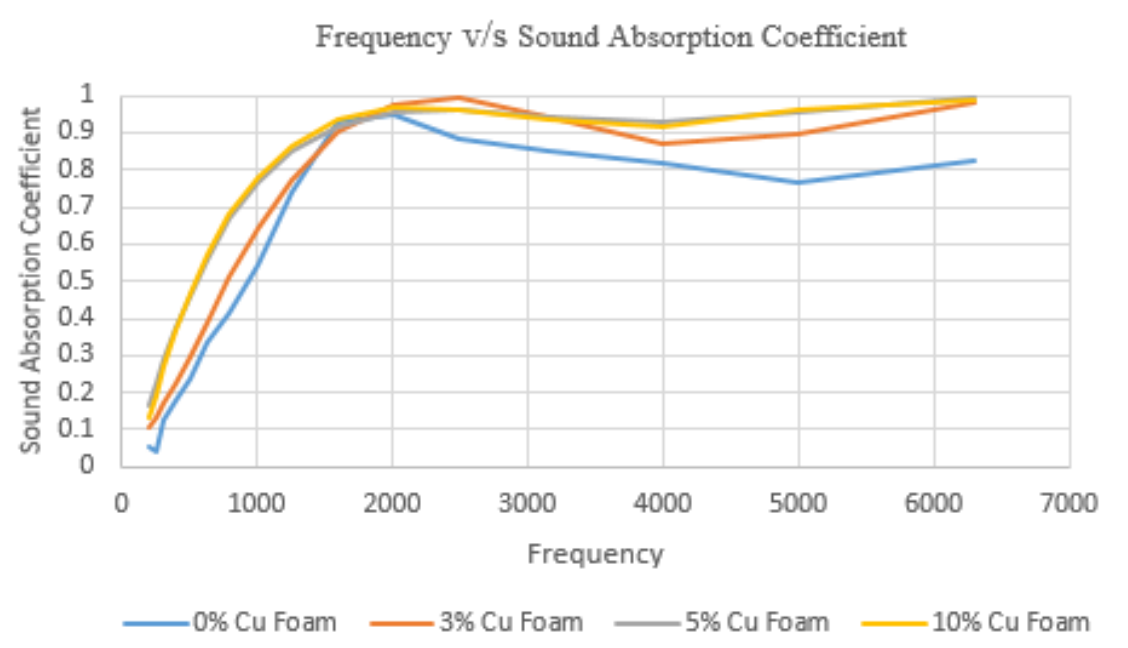

Figure 13. Comparison of Acoustic Shielding of different proportions

$\mathrm{Cu}$ in sustainable foam

The presence of Copper powder has made a positive effect over the result of sound absorption coefficient. The sound absorption coefficient of $10 \% \mathrm{Cu}$ reinforced foam is maximum among all the samples. $10 \% \mathrm{Cu}$ reinforced foam is more porous in comparison to the other samples in fact the porosity of the sample increases with the increase in the $\mathrm{Cu}$ percentage thus increasing the inclusion of air gaps and so increasing the sound absorption coefficient. Also the sound absorption coefficient is more at higher frequencies in comparison to lower frequencies. At frequencies tending to $6000 \mathrm{~Hz}$ the sound absorption coefficient tends to 1 and for frequencies tending to $200 \mathrm{~Hz}$ the sound absorption coefficient is around 0.1 .

\section{Thermal conductivity test}

Table 3. Test Observations of Thermal Conductivity

\begin{tabular}{|c|c|}
\hline Sample & Thermal Conductivity $\left(\mathbf{W m}^{-1} \mathbf{k}^{-1}\right)$ \\
\hline Non reinforced foam & 0.02 \\
\hline Reinforced foam $(3 \% \mathrm{Cu})$ & 0.1928 \\
\hline Reinforced foam $(5 \% \mathrm{Cu})$ & 0.1863 \\
\hline Reinforced foam $(10 \% \mathrm{Cu})$ & 0.1802 \\
\hline
\end{tabular}


From Table 3., we can see that the thermal conductivity of reinforced foam is greater than that of non-reinforced foam. This can be accounted from the fact that copper is a good conductor of heat and its inclusion in the foam increases the net thermal conductivity of the sample. But due to increase in the porosity of the foam with increase in the $\mathrm{Cu}$ percentage creates more air gaps in $10 \%$ reinforced sample than $5 \%$ sample and $3 \%$ sample so there is a decrease in the thermal conductivity with increase in the $\mathrm{Cu}$ percentage [9].

\section{CONCLUSIONS}

- $\quad$ Copper powder reinforced forms with three different proportions of copper were prepared. The flexible foams primarily contain polyol and isocyanides with 2:3 proportions.

- $\quad$ The physical and chemical properties of the samples are characterized and the sound absorption coefficient is characterized using Acoustic performance test setup. The maximum sound absorption coefficient of the flexible foams with copper powder was observed to be around 0.9952 for $10 \% \mathrm{Cu}$ reinforced at $6300 \mathrm{~Hz}$. The sound absorption coefficients were lower at lower frequency sound range.

- Though there were increase in the thermal conductivity of $\mathrm{Cu}$ powder reinforced foams but still due to more porosity the thermal conductivity of $10 \% \mathrm{Cu}$ reinforced was less in comparison to $3 \%$ and $5 \% \mathrm{Cu}$ reinforced foams.

- $\quad$ So finally, $10 \% \mathrm{Cu}$ reinforced foam has better Sound absorption coefficient as well as less thermal conductivity so it can be used for insulating building walls from sound and heat. Also it can be used as an insulation of walls of vehicles or even that of spaceships.

\section{ACKNOWLEDGEMENT}

We are thankful to VIT-CHENNAI for providing us with resources and fully equipped laboratory for carrying out the experiments. We are also thankful to the Dr. Inderjeet (Associate Professor) Crescent University Chennai for helping with test setup and carrying out experiment.

\section{REFERENCES}

[1] Alam, J.B., Jobair.J. Rahman.M.M, Dikshit. A.K. and Khan S.K. Study on traffic noise level of sylhet by multiple regression analysis associated with health hazards II , Iran. J.Environ. Health. Sci.Eng., 2006; 3( 2):71-78.

[2] Murthy,V.K., Khanal, S.N., Assessment of traffic noise pollution in Banepa, a semi urban town of Nepal, Kathmandu university,Journal of science, engineering and technology, 2007;1:1-9

[3] Ohrstrom, E., Bjorkman, M., and Rylander, R., "Subjective Evaluation of Work Environment with Special Reference to Noise", Journal of Sound and Vibration, Volume 65, No. 2, pp. 241-249, 1979.

[4] Bhatt, S.R., Subrahmanyam, K., and Swami, K.R., "Noise Pollution in Textile Industry", A Review Report by ATIRA, Ahmedabad, 1990

[5] Sound absorption analysis of castor oil based polyurethane foamwith natural fiber, Yuvaraj.La ,S.Jeyanthi*a, M.C.Lenin Babua ,a Vit University Chennai Campus-600127,India.

[6] Schellnhuber, H. J. (2008). Global warming: Stop worrying, start panicking? Proceedings of the National Academy of Sciences, 105(38), 14239-14240.doi:10.1073/pnas.0807331105

[7] Tseng, C., Yamaguchi, M., \& Ohmori, T. (1997). Thermal conductivity of polyurethane foams from room temperature to $20 \mathrm{~K}$. Cryogenics, 37(6), 305-312.doi:10.1016/s0011-2275(97)00023-

[8] Sparks, L.L. and Arvidson, J.M., Thermal and mechanical properties of polyurethane foams and a survey of insulating concretes at cryogenic temperatures. Report NTIS PB85-100949, National Bureau of Standards, Boulder, CO, 1984.

[9] FRANCL, J., \& KINGERY, W. D. (1954). Thermal Conductivity: IX, Experimental Investigation of Effect of Porosity on Thermal Conductivity. Journal of the American Ceramic Society, 37(2), 99107.doi:10.1111/j.1551-2916. 1954.tb20108.x

[10] Akindoyo, J. O., Beg, M. D. H., Ghazali, S., Islam, M. R., Jeyaratnam, N., \& Yuvaraj, A. R. (2016). Polyurethane types, synthesis and applications - a review. RSC Advances, 6(115), 114453-114482.doi:10.1039/c6ra14525f. 